\title{
THE PERCEPTION OF WROCLAW AS A LIVEABLE CITY
}

\author{
MAGDALENA DASZKIEWICZ \\ Wroclaw University of Economics, Faculty of Economic Science, \\ Department of Marketing Research, Komandorska 118/120, 53-345 Wroclaw, Poland \\ email: magdalena.daszkiewicz@ue.wroc.pl
}

EDYTA MAZUREK

Wroclaw University of Economics, Faculty of Management, Computer Science and Finance, Department of Statistics, Komandorska 118/120, 53-345 Wroclaw, Poland email: edyta.mazurek@ue.wroc.pl

\begin{abstract}
Contemporary cities face the increasing global competition and the necessity to take actions for retaining and attracting residents, tourists, business and investments and highly qualified human capital. Retaining and attracting talented young people may be at the heart of growing a high prosperity of cities. As we know young people are the most likely demographic group to move. The primary challenge for cities is to create places that young talents not only visit, but also treat as attractive places to study, work and live. Therefore, it is important to conduct studies to identify factors affecting city liveability perception and people's decisions regarding the choice of a city as a place to live, study and work.

The main aim of the paper is to determine the perception of Wroclaw's attractiveness as a city to live and identify the impact of selected factors affecting city liveability perception. The logit model is used for the assessment of the effects of explanatory factors on the chance that Wroclaw is perceived as a good place to live. The analysis is made basing on real data from the survey on the attractiveness of Wroclaw through the eyes of international students. We focused on evaluating the overall perception of the liveability of the city, in relation to perception of Wroclaw's liveability for different groups of residents. We also tested if perception of Wroclaw as a liveable city depends significantly on the national wealth of home country of international students. We discuss the findings and provide some managerial implications regarding city development and implications for future research.
\end{abstract}

Key words: city attractiveness, city liveability, perceived liveability, logit model, categorical data

JEL Codes: C31, C35, M38, H79, Z13

\section{DOI: $10.15611 / a m s e .2017 .20 .06$}

\section{Introduction}

The basic challenge for management of cities is to strengthen their capacity to adapt to the changing marketplace, seize opportunities, and sustain their validity (Kotler et al., 1993). The increasing global competition forces cities' authorities to consider and take actions for retaining and attracting residents, tourists, highly qualified human capital, business and investments.

In simple terms, city attractiveness can be considered on three dimensions that relate to the city capacity to maintain and attract residents (liveability), visitors (visitability), business and investment (investability) (Kotler et al., 1999). Most studies on the perceived attractiveness of 
places focus on evaluating different aspects of perceiving places as tourist destinations. It is important to conduct studies to identify factors affecting city liveability perception and people's decisions regarding the choice of a city as a place to live, study and work. In the paper we address the issues of liveability and its perception in a case of polish city - Wroclaw.

As worded by Florida (2008, p. 90): "Today what matters most isn't where most people settle, but the greatest numbers of most skilled people locate". Retaining and attracting talented people may be at the heart of growing a high prosperity of cities. This means not only investments in life quality of a city but also communicating place features, life quality and achievements for the purpose of creating a strong image. There are strong reasons for focusing on young, educated people who represent the potential for urban development.

Mahroum (2000) divided international talent into five groups: managers \& executives, engineers \& technicians; academics \& scientists; entrepreneurs and students, and students are considered as main supply channels to all these groups. Therefore, cities aiming to attract talents from other countries should pay attention to attract international students and encourage them to choose them as a place to live and work after their studies. It's worth noting here, young people form the demographic group most likely to move, and in recent years we can observe the increase in migration of students (People in the EU - statistics on geographic mobility, 2015).

The study addresses the issue of perception of Wroclaw as a place to live and the importance of evaluation criteria of city liveability. We focused on evaluating the overall perception of the liveability of the city, in relation to perception of Wroclaw's liveability for different groups of residents.

We identify the impact of selected factors (place attributes) affecting Wroclaw's liveability perception. We also test if perception of Wroclaw as a liveable city depends significantly on the national wealth of home country of international students. We discuss the findings and provide some managerial implications regarding city development and implications for future research.

\section{Liveability perception - a measurement challenge}

Liveability is the concept that relate to the city capacity to maintain and attract residents (Kotler et al., 1999). According to the Economist Liveability Ranking, "the concept of liveability is simple: it assesses which locations around the world provide the best or the worst living conditions" (A Summary of the Liveability Ranking and Overview, 2016, p. 7). The short definition, aptly describing the sense of liveability is provided by the Merriam-Webster dictionary, where liveabilty is defined as "suitability for human living" (Merriam-Webster, 2017). As defined in the report State of the English Cities (2006) the liveability agenda is essentially about creating places where people choose to live and work (now an in the future).

The measurement of liveability may combine objective information with opinions. We should not base an assessment of liveability with the exclusive use of objective indicators. Many important aspects of people's lives do not lend themselves to objective measurement, such as the environmental beauty, feelings of security (or insecurity) or the quality of the community relations (Lora and Powell, 2011). The good life is much more than a commodity to be produced, distributed and consumed (Massam, 2002), therefore the liveability results not only from the objective characteristics of the place of residence but also from the subjective assessment. As defined by Cutter (1985): quality of life is an individual's happiness or satisfaction with life and environment, including needs and desires, aspirations, lifestyle preferences and other tangible and intangible factors which determine wellbeing. So it includes both tangible and intangible measures reflecting local consensus on the community's values and goals. In this context, the concept of liveability and quality of life can be regarded 
as closely related. Considering the subjective side of liveability and quality of life are linked to the notions of a good life, a valued life, a satisfying life and a happy life (Feneri et al., 2013, Henchoz et al., 2015, Rybakovas, 2016, Scogin at al., 2016).

Therefore, apart from objective measurements of quality of life, based on data from various statistical sources, there are also studies on the perception of the attractiveness of cities as a place to live. Research on places' perception can be conducted based on functional characteristics and psychological characteristics (Crouch and Ritchie, 2003). Functional characteristics concern the more tangible aspects (such as landscape, climate, attractions, price level) and psychological characteristics concern the more intangible aspects (such as friendliness, sense of security, atmosphere, cultural distinctness/similarity).

Of course, limitations of the subjective measurement must be taken into account, because respondents expressing their subjective opinions about cities have different access to information, various experiences, cultural biases or aspirations. It should be noted, that international monitoring systems (including Eurostat' Urban Audit) increasingly involve perception studies in their surveys on quality of life in cities (Survey on quality of life, 2010). It is largely down to the fact that many aspects of quality of life are qualitative in nature.

Some researchers attempt to employ objective and subjective information jointly and propose solutions to resolve the problems resulting from the use of a combination of both kinds of information. Lora and Powell (2011) suggest identification and ranking the issues of potential importance for urban dwellers. One of the methods may be the calculation of an implicit price for various attributes (a monetary value on city characteristics), which again may yield a scheme to weight variables to generate an aggregate index.

The performed measurements may regard overall perception (holistic image) and characteristic attributes. The research process may lead to capturing unique attributes and "common" features, which might characterise also other cities and may be used for the purpose of comparison (Echtner and Ritchie, 2003). Researchers use various lists of attributes to measure the perception of cities. Various comparative studies of cities are conducted, leading to city rankings creation. Most of them concern large cities.

The Urban Audit system of Eurostat monitored the quality of life in 357 cities with more than 300 indicators more aligned to residents' likes and dislikes, e.g., demography, housing, health, crime, labour market, income disparity, local administration, educational qualifications, environment, climate, travel patterns, information society and cultural infrastructure (Feldman, 2008).

One of the most significant studies on perceptions of city liveability was the Urban Audit Perception Survey. The study consisted of 22 questions, categorized in the following 8 categories: employment opportunities, housing costs, safety, cleanliness of cities, public transport, air pollution, integration of immigrants and overall satisfaction with the quality of life of their city. The perception surveys, conducted in 2004 and 2005, allow for comparisons between perceptions and "real" data from various statistical sources on issues such as urban security, unemployment and air quality (Urban Audit Perception Survey, 2005).

In the "Survey on perception of quality of life in 75 European cities" the interviewed inhabitants expressed their views on the quality of life in their home city (Survey on perception of quality of life in 75 European cities, 2010). The study introduced new questions to assess people's perception of public spaces in their city (such as markets, squares and pedestrian areas) and possibilities for outdoor recreation (such as walking and cycling), transport modes and the usage of public transport, perception of poverty problem, a level of trust to the inhabitants.

Recent research on the quality of life in cities commissioned by the European Commission (Quality of Life in European Cities, 2016), include the following categories: people's 
satisfaction with living in their city (the overall satisfaction, satisfaction with infrastructure and facilities of the city: public transport, health care services, sports facilities, cultural facilities, educational facilities, streets and buildings, public spaces, availability of retail shops), people's views about their city (employment opportunities, the housing situation, the presence and integration of, safety and trust, city administrative services), people's satisfaction with their city in relation with environment (air quality, noise level, cleanliness, green spaces, fight against climate change), people's satisfaction with their personal situation (life in general, place where people live, financial situation of household, personal job situation).

The Place and Happiness Survey covered many liveability attributes, which were grouped into 5 major categories: physical and economic security (perceptions of crime and safety, availability of jobs, the overall direction of economy), basic services (schools, healthcare, affordable housing, roads, public transportation), leadership (the quality and efficacy of leadership and public and local engagement), openness (the level of tolerance for and acceptance pf diverse groups), aesthetics (physical beauty, amenities, cultural offering) (Florida, 2008).

In the Economist Intelligence Unit's liveability rating every city is assigned a rating of relative comfort for over 30 qualitative and quantitative factors across five broad categories: stability (prevalence of petty crime, prevalence of violent crime, threat of terror, threat of military conflict threat of civil unrest/conflict), healthcare (availability of private healthcare, quality of private healthcare, availability of public healthcare, quality of public healthcare, availability of over-the-counter drugs, general healthcare indicators), culture and environment (humidity/temperature, conditions, discomfort of climate to travellers, level of corruption or religious restrictions, level of censorship, sporting availability, cultural availability, food and drink, consumer goods and services), education (availability of private education, quality of private education, public education indicators) and infrastructure (quality of road network, public transport, quality of international links, availability of good quality housing, quality of energy provision, quality of water provision, quality of telecommunications). As a result, EIU liveability Index is calculated for each surveyed city (A Summary of the Liveability Ranking and Overview, 2016). In 2012 Filippo Lovato (Best cities ranking and report, 2012) proposed extending the measurement to the sixth category - spatial characteristics (green space, sprawl, natural assets, cultural assets, connectivity, isolation, pollution), recognizing them as important ingredients in liveability. In this way a Spatial Adjusted Liveability Index was created.

Mercer Quality of Living Ranking (2017) evaluates local living conditions in more than 450 cities surveyed worldwide. Living conditions are analysed according to 39 factors, grouped in 10 categories: political and social environment (political stability, crime, law enforcement, etc.), economic environment (currency exchange regulations, banking services), socio-cultural environment (media availability and censorship, limitations on personal freedom), medical and health considerations (medical supplies and services, infectious diseases, sewage, waste disposal, air pollution, etc.), schools and education (standards and availability of international schools), public services and transportation (electricity, water, public transportation, traffic congestion, etc.), recreation (restaurants, theatres, cinemas, sports and leisure, etc.), consumer goods (availability of food/daily consumption items, cars, etc.), housing (rental housing, household appliances, furniture, maintenance services), natural environment (climate, record of natural disasters).

The researchers use different measurement methods, various attributes and they base the city rating on the various indicators. What is evident is that even the list of measured categories varies, the researches focus on similar elements. The employment of indicators in 
liveability research ensures greater clarity, enables statistical analyses and multi-dimensional comparisons. But the development of a universal set of indicators that which allow making full worldwide comparisons among cities seems to be extremely difficult, due to huge differences which exist in geographical, economic and socio-cultural contexts. Researchers face problems with selecting appropriate measurement criteria and reducing their number in order not to cause excessive elaboration of measurement instruments. This results in risks related to the failure to take into consideration important criteria and excessive elaboration of the measurement criteria that are less significant in liveability evaluation.

In addition to the comparisons between cities, in a comparative approach to liveability measurements, we can also study the liveability of a city over time and make measurements in different groups. Both those who had direct contact with a given city (who lived there, visited it) and those who did not have such an opportunity can have different perceptions of the place. The research regarding perceptions of a place can be conducted in various recipient groups, and its results may be subject to comparisons (Prentice and Andersen, 2000). It's also important to measure the overall perception and tendency to recommend a city, which may result from a good perception of the city as a place to live.

Due to migration phenomena, the research on perceived liveability of cities among those who choose to change their place of residence seems to be of particular interest. Taking into account the increased mobility of young people and the importance of attracting talent for urban development, in our paper we focused on a group of international students and their perception of Wroclaw as a liveable city.

\section{Statistical research}

The main objective of conducted statistical analysis was to answer the statistical questions: what are the factors that influence the overall perception of Wroclaw as a good or very good place to live, and how this influence is exerted? What is the influence of the selected factors on the perception of Wroclaw as a good or very good place to live? We answered the questions using the results of online survey conducted among 315 respondents. The research sample included international students who had studied in Wroclaw under the Erasmus Plus programme and spent at least one semester in the city in the period 2015-2016. A questionnaire with 22 closed questions was addressed to international students through coordinators of the Erasmus Plus programme of Wroclaw universities.

The study concerned the perception of the city of Wroclaw. Wroclaw is a city situated in southwest Poland and the capital city for the region of Lower Silesia. With a population of 630,000 (1.1 million including the wider metropolitan area) it is the fourth largest city in Poland. Wroclaw is an important polish centre of the economy, as well as culture, education, science and tourism. With the number of inhabitants increasing by around $11 \%$ in the last ten years, it is a motor for the development of Lower Silesia (http://urbact.eu/wroclaw\#).

\subsection{Description of data}

We surveyed 315 students who came to Wroclaw to participate in their Erasmus programmes. The students from 31 countries accomplished a part of their studies in one of the following universities in Wroclaw:

- Wroclaw University of Economics,

- Wroclaw University of Science and Technology,

- University of Wroclaw,

- Wroclaw University of Environmental and Life Sciences,

- University School of Physical Education in Wroclaw (AWF). 
- Academy of Music in Wroclaw,

- Wroclaw Medical University.

More than 56 percent of the sample was composed by students hosted by the Wroclaw University of Economics. The surveyed students responded to 22 questions that will be explained as they actually applied in the statistical analysis.

Baseline characteristics of respondents are presented in Table 1.

Table 1: Percentage frequency for the basic characteristics of respondents

\begin{tabular}{lll}
\hline Variable/Question & Category & Percent [\%] \\
\hline Gender: & Female & 41.6 \\
& Male & 58.4 \\
\hline Have you already been to & Yes & 27.3 \\
Poland: & No & 72.7 \\
\hline Have you already been to & Yes & 9.5 \\
Wroclaw: & No & 90.5 \\
\hline
\end{tabular}

Source: own elaboration.

The study sample consists of $41.6 \%$ women and $58.4 \%$ men. $27.3 \%$ of respondents visited Poland before choosing their place of study, $72.7 \%$ - did not. Only $9.5 \%$ of the respondents were in Wroclaw before the choice of the city as a place of study. Table 2 presents descriptive statistics of age.

Table 2: Descriptive statistics for age

\begin{tabular}{cccccc}
\hline Mean & Min & Max & Moda & Median & Variance \\
\hline 23.2 & 18 & 35 & 22 & 23 & $10.7 \%$
\end{tabular}

Source: own elaboration.

The surveyed students are in the age range from 18 to 35 . The average age of the respondents is 23.2 years. The median equals 23 , so $50 \%$ of respondents are 23 years old or less, and $50 \%$ examined students are 23 years old or more. Most of the surveyed students are 22 years old. The survey was conducted on a sample of Erasmus program students, which was a fairly homogeneous group in terms of age (variance equals $10.7 \%$ ). Each respondent answered the 22 questions described in the point 3.3.

\subsection{Methodology}

In order to indicate the variables which are significant in the perception of Wroclaw as a liveable city (the response variable), the following null hypotheses claiming the independence between two variables were tested:

$$
H_{0}: \forall i=1,2, \ldots, I \quad \forall j=1,2, \ldots, J \quad p_{i j}=p_{i \bullet} p_{\bullet j}
$$

i.e. variables under study are independent, with the alternative hypothesis:

$$
H_{1}: \exists i=1,2, \ldots, I \quad \exists j=1,2, \ldots, J \quad p_{i j} \neq p_{i \bullet} p_{\bullet j}
$$

i.e. variables under study are dependent, 
where $I$ and $J$ denote the numbers of rows and columns in a contingency table created for the two variables under study. To test these hypotheses, one of the following test statistics was applied:

likelihood ratio:

$$
V=2 \sum_{i=1}^{I} \sum_{j=1}^{J} n_{i j}\left(\ln n_{i j}-\ln e_{i j}\right)
$$

Pearson's $\chi^{2}$ :

$$
\chi^{2}=\sum_{i=1}^{I} \sum_{j=1}^{J} \frac{\left(n_{i j}-e_{i j}\right)^{2}}{e_{i j}},
$$

Yates's correction for Pearson's $\chi^{2}$ :

$$
\chi_{\text {Yates }}^{2}=\sum_{i=1}^{I} \sum_{j=1}^{J} \frac{\left(\left|n_{i j}-e_{i j}\right|-0,5\right)^{2}}{e_{i j}},
$$

where $e_{i j}=\frac{n_{i \bullet} n_{\bullet j}}{n}$ denotes the theoretical, expected frequency if variables are independent.

For sufficiently large $n$ the above test statistics (2)-(4) follow the asymptotic chi-squared distribution with $(I-1)(J-1)$ degrees of freedom. When expected frequencies are small, then the type II error probability increases, therefore the above tests were conducted with a large sample of 315 observations, and in compliance with the rules presented in Table 3.

Table 3: Application conditions of the test statistic

\begin{tabular}{ll}
\hline Expected frequencies & The type of test \\
\hline All frequencies $>10$ & Chi-squared \\
When any frequency $<10$ & V-squared (the likelihood-ratio test) \\
When any frequency $<5$ & Chi-squared with Yates' correction \\
\hline
\end{tabular}

Source: own elaboration.

For more detailed examination of the influence exerted on perception of Wroclaw as a liveable city by remaining variables the following logit model was applied:

$$
\operatorname{logit}\left(p_{i}\right)=\log \left(\frac{p_{i}}{1-p_{i}}\right)=\beta_{0}+\beta_{1} \cdot x_{1 i}+\ldots+\beta_{k} \cdot x_{k i}
$$

The estimators of the coefficients are found by maximum-likelihood method. A Wald test:

$$
W=\frac{\hat{\beta}_{i}}{\sqrt{\operatorname{Var}\left(\hat{\beta}_{i}\right)}} \sim_{H_{0}} N(0,1)
$$

is used to test the statistical significance of each coefficient $\left(\beta_{i}\right)$ in the model (5):

$$
\begin{aligned}
& H_{0}: \beta_{i}=0 \\
& H_{1}: \beta_{i} \neq 0 .
\end{aligned}
$$

The likelihood-ratio test and the Wald test were used to select the model which is best fitted to the data. Since logistic regression calculates the probability of success $\left(p_{i}\right)$ over the probability of failure $\left(1-p_{i}\right)$, the results of the analysis are in the form of an odds ratio. Logistic regression provides knowledge of the relationships and strengths among the variables. 


\subsection{Results of the analysis}

The perception of Wroclaw as a liveable city (a dependent variable) was denoted by $Y$ and defined as follows:

$$
y=\left\{\begin{array}{lll}
1 & \text { if } & \text { a student rates Wroclaw as a good or very good place to live, } \\
0 & \text { otherwise. }
\end{array}\right.
$$

The first working hypothesis in the research was a conjecture that a student's perception of Wroclaw as a liveable city depends significantly on the national wealth of his or her home country. In order to test this hypothesis, the categorization of countries into three groups was put forward:

1. Countries approximately as rich as Poland.

2. Countries significantly richer than Poland.

3. Countries significantly poorer than Poland.

Gross domestic product at purchasing power parity per capita prepared by the International Monetary Fund was adopted as the measure of countries' wealth (World Economic and Financial Surveys). Next, typical countries were defined in the context of wealth similar to that of the host country selected for a part of studying programme, i.e. to Poland. As a result, the interval containing the GDP (PPP) per capita, in international dollars, in countries close to Poland (Davies and Gather, 1993):

$$
G D P_{P O L A N D}+1.5 \cdot I Q R<G D P<G D P_{P O L A N D}+1.5 \cdot I Q R
$$

where

$G D P_{P O L A N D}$ - GDP (PPP) per capita in Poland,

$I Q R$ - the difference between the 1 st quartile and the 3rd quartile, i.e. $I Q R=Q_{3}-Q_{1}$.

The countries with GDP per capita from the interval

$$
(15,176 ; 37,822)
$$

were assumed to be approximately as rich as Poland. The countries with GDP lower than the left endpoint of (9) were assumed as poorer, and those with GDP greater than the right endpoint of (9) as richer than Poland. Accordingly, the variable GDP was defined:

$$
G D P=\left\{\begin{array}{lll}
1 & \text { if } & \text { GDP per capita } \leq 15,176 \\
2 & \text { if } & 15176<\text { GDP per capita }<37,822 \\
3 & \text { if } & \text { GDP per capita } \geq 37,822
\end{array}\right.
$$

In order to test the hypothesis that the perception of Wroclaw as a liveable city depends on the wealth of the student's home country, the test (3) was applied with respect to $y$ and GDP, and the value of test statistic was found to be 2.24 , with the $p$-value equal 0.321 . This result contradicted our hypothesis, hence the wealth of the student's home country is not significant for his or her perception of Wroclaw as a liveable city. In a similar way the remaining variables were tested as regards their influence on the perception of Wroclaw as a liveable city for the following kinds of people:

- Students (denoted by student),

- Families with children (denoted by family),

- Racial and ethnic minorities (denoted by minority),

- Gay and lesbian people (denoted by gay), 
- Immigrants from other countries (denoted by immigrant),

- Senior citizens (denoted by senior),

- People living below poverty (denoted by poor),

- Young single people (denoted by young),

- Recent university/college graduates looking for work (denoted by graduate).

During the survey respondents rated the attractiveness of the city for each category of people. The results of testing the independence between $y$ and the above variables are presented in Table 4.

Table 4: Determinants of perceiving Wroclaw as a liveable city.

\begin{tabular}{lcl}
\hline Variable & The value of the test statistic & p-value \\
\hline $\boldsymbol{G D P}$ & 2.27 & 0.3210 \\
student & 41.90 & 0.000 \\
family & 77.95 & 0.000 \\
minority & 11.66 & 0.009 \\
gay & 6.56 & 0.087 \\
immigrant & 17.74 & 0.001 \\
senior & 20.57 & 0.0001 \\
poor & 0.50 & 0.918 \\
young & 64.37 & 0.000 \\
graduate & 21.92 & 0.00007 \\
\hline
\end{tabular}

Source: own elaboration.

The research findings in Table 4 demonstrate that overall perception of Wroclaw as a liveable city does not depend on whether respondents perceive the city as a good place to live for gay and lesbian people or poor inhabitants (p-value exceeds 0.05). In addition, as shown above, the wealth of the home country of respondents does not affect the perception of Wroclaw as a liveable city.

Respondents also answered the question how do they rank the attractiveness of Wroclaw the following aspects:

- overall beauty/physical environment (denoted by overall),

- possibility of meeting new people (denoted by meeting),

- infrastructure in general (denoted by infrastructure),

- public transportation (denoted by public),

- cost of living (denoted by cost),

- openness towards foreigners (denoted by openness),

- nightlife (denoted by nightlife),

- parks and open space (denoted by parks),

- cultural and recreational offerings and leisure possibilities (denoted by relax),

- physical security and perceived safety (denoted by safety),

- cleanliness and weather conditions (denoted by weather).

For each attributes the respondent could choose one of two possible responses: (high or very high) or (moderate or low). The test for independence according to the conditions in Table 3 was used to select the attributes which influence on the positive perception of Wroclaw as a liveable city. 
All studied attributes of the city except for nightlife and cost were considered important in the city's assessment and had a strong impact on the positive perception of the city as a place to live ( $\mathrm{p}$-values $<0.001$ ).

In order to examine more details of the influence exerted on perceiving Wroclaw as a liveable city by remaining variables, i.e. those denoted by student, family, minority, immigrant, senior, young, and graduate, the logit model (5) was applied. The likelihood-ratio test and the Wald test were used to select the model which is best fitted to the data. The selected model (11) comprised the variables shown in table 5. Table 5 also presents the estimates of parameters with standard errors of estimation, and $p$-values for the Wald test.

Table 5: Logit model estimation results.

\begin{tabular}{llllll}
\hline $\mathrm{N}=315$ & constant & family & young & overall & relax \\
\hline Estimate & 0.6398 & 0.6699 & 0.8934 & 0.6612 & 0.7016 \\
Standard error & 0.2450 & 0.2049 & 0.2355 & 0.2147 & 0.2022 \\
$p$-value & 0.0094 & 0.0012 & 0.0002 & 0.0023 & 0.0006 \\
\hline
\end{tabular}

Source: own elaboration.

$$
\operatorname{logit}\left(p_{i}\right)=\log \left(\frac{p_{i}}{1-p_{i}}\right)=0.64+0.67 \cdot \text { family }+0.89 \cdot \text { young }+0.66 \cdot \text { overall }+0.7 \cdot \text { relax }
$$

Each explanatory variable is coded either as " 1 " when the respondent perceived Wroclaw as a good or very good city to live for a given group of people, or "-1" otherwise. Such coding of variables and the positive sign of the indicator variable's coefficient imply that the good and very good perception of Wroclaw as a city to live for families and young people increase the chances of Wroclaw to be perceived as a liveable city. The most important for the chances of Wroclaw to be perceived as a liveable city are also the following aspects of the attractiveness of Wroclaw: physical environment and leisure possibilities.

Based on the estimated logit model, the likelihood ratios of chances of Wroclaw to be perceived as a liveable city for families and young people compared to the groups of people who evaluate Wroclaw as a bad place to live in are as follows:

$$
\begin{aligned}
& \psi_{\text {family }(1) / \text { family }(-1)}=\frac{\exp (0.64+0.67)}{\exp (0.64-0.67)}=\exp (1.34)=3.82 \\
& \psi_{\text {young }(1) / \text { young }_{(-1)}}=\frac{\exp (0.64+0.89)}{\exp (0.64-0.89)}=\exp (1.78)=5.93
\end{aligned}
$$

Based on the estimated logit model, the likelihood ratios of chances of Wroclaw to be perceived as a liveable city for students appraising Wroclaw highly in terms of overall beauty or leisure possibilities compared to the students rating Wroclaw low in that respect are as follows:

$$
\begin{aligned}
& \psi_{\text {overall }(1) / \text { overall }(-1)}=\frac{\exp (0.64+0.66)}{\exp (0.64-0.66)}=\exp (1.32)=3.74 \\
& \psi_{\text {relax }(1) / \text { relax }(-1)}=\frac{\exp (0.64+0.7)}{\exp (0.64-0.7)}=\exp (1.78)=4.06
\end{aligned}
$$


All the variables increase the chances of Wroclaw to be perceived as a liveable city more than threefold.

\section{Conclusions}

The conducted analysis implies that in the group of students, who came to Wroclaw to study under the Erasmus programme, Wroclaw is perceived as a good place to live. The overall perception of its liveability is mostly influenced by the perception of Wroclaw as a liveable city for families and young people. The perception of Wroclaw as a good place of residence for young people increases the chances of Wroclaw to be perceived as liveable city nearly sixfold, and for families - nearly fourfold.

What is significant is that the wealth of the home country of students does not affect the perception of Wroclaw as a liveable city.

The study was also concerned with the impact of selected factors (place attributes) affecting Wroclaw's liveability perception. Respondents were asked about importance and assessment of the following city attributes: overall beauty (physical environment), possibility of meeting new people, infrastructure in general, public transportation, cost of living, openness towards foreigners, nightlife, parks and open space, cultural and recreational offerings and leisure possibilities, physical security and perceived safety, cleanliness and weather conditions. The high evaluation of Wroclaw in the context of the overall beauty encourages their potential settlement in Wroclaw, because it increases the chances of Wroclaw to be perceived as a liveable city nearly fourfold compared to respondents rating Wroclaw low in that respect. The high rating of Wroclaw as a good place to live is also related to the high rating of the city in terms of leisure possibilities.

In future research we can also deal with the measurement of changes in the perception of particular attributes over time. It would be interesting to compare the subjective assessments of individual factors with the assessment of attributes based on objective metrics. We should also consider research that allows for comparison of the objective evaluation of changes with the results of perception studies.

Erasmus students perceive Wroclaw mostly considering their nearest perspective, i.e. the circumstances of Wroclaw making the city a good place to live in by young people and families. These aspects should be considered by the municipal government in order to encourage young people to choose Wroclaw as a place to establish families and to find jobs, and as a result to participate in the development of Wroclaw and the region.

The results of the study show that for the perception of liveability of the city in the group of young people it does not matter whether it is a good place to live for seniors. This result may be the basis for further comparative studies on the perception of the city as a place of living for different groups of people (especially young people and seniors). In the context of sustainable urban development and demographic trends, it is worth to think about "making cities liveable for all ages", that's why it's important to compare the perceptions and expectations in different age groups. The challenge for city authorities is to seek and implement management solutions that combine the expectations and interests of different groups, as well as conduct appropriate communication activities, which would contribute to the perception of liveability of the city.

\section{Acknowledgements}

The authors are grateful to an anonymous referee for their constructive comments and suggestions. Any errors are solely those of the authors. 


\section{References}

[1] Agresti A. 2002. Categorical Data Analysis John Wiley \& Sons, Inc.,New Jersey.

[2] A Summary of the Liveability Ranking and Overview, A report by The Economist Intelligence Unit. 2016. [cit. 10.03.2017] http://pages.eiu.com/rs/783-XMC194/images/Liveability_August2016.pdf.

[3] Best cities ranking and report. A special report from the Economist Unit. 2012. [cit. 10.03.2017] http://pages.eiu.com/rs/eiu2/images/EIU_BestCities.pdf.

[4] Crouch G.I., Ritchie J.R.B. 2003. The Competitive Destination, Cambridge, CABI Publishing, 195.

[5] Cutter, S. L. 1985. Rating places: A geographer's view on quality of life. Washington, D.C: Association of American Geographers.

[6] Davies L., Gather U. 1993. The Identification of Multiple Outliers, Journal of the American Statistical Association, Volume 88, Issue 423, pp. 782-792.

[7] Echtner Ch.M., Ritchie, J.R.B. 2003. The meaning and measurement of destination image, The Journal of Tourism Studies, 14(1), pp. 40-44.

[8] Feldmann B. 2008. The Urban Audit-Measuring the Quality of Life in European Cities, Eurostat, Statistics in Focus. www.epp.eurostat.ec.europa.eu/cache/ITY_OFFPUB/KSSF-08-082/EN/KS-SF-08-082-EN.PDF, cited in: Lora E., Powell, A. (2011) : A New Way of Monitoring the Quality of Urban Life, IDB Working Paper Series, No. IDB-WP272.

[9] Feneri A.M, Vagiona D., Karanikolas N. 2013. Measuring quality of life (QOL) in urban environment: An integrated approach. Proceedings of the 13th International Conference on Environmental Science and Technology Athens, Greece, 5-7 September 2013. [cit. 11.12.2016] http://www.gnest.org/proceedings/cest2013/public_html/papers/0294.pdf.

[10] Florida R. 2008. Who's your city? How creative economy is making where to live the most important decision of our life, New York.

[11] Henchoz Y., Meylan L., Goy R., Guessous I., Bula C., Demont M., Rodondi N., Santos-Eggimann B. 2015. Domains of importance to the quality of life of older people from two Swiss regions. Age Ageing, 44(6), 979-85.

[12] http://urbact.eu/wroclaw\# [cit. 23.02.2017].

[13] World Economic and Financial Surveys. [cit. 10.03.2017] http://www.imf.org/external/pubs/ft/weo/2016/01/weodata/weorept.aspx.

[14] Kotler P., Asplund C., Rein I., Haider D. 1999. Marketing Places Europe. Pearson Education Ltd, London.

[15] Kotler, P., Haider, D. and Rein, I. 1993. Marketing Places: Attracting Investment, Industry, and Tourism to Cities, States, and Nations, The Free Press, New York.

[16] Lora E., Powell, A. 2011 : A New Way of Monitoring the Quality of Urban Life, IDB Working Paper Series, No. IDB-WP-272. [cit. 10.03.2017]

http://hdl.handle.net/10419/88983.

[17] Mahroum, S. (2000). Highly skilled globetrotters: Mapping the international migration of human capital, R\&D Management,30(1), 23-31. 
[18] Massam B.H. 2002. Quality of life: Public planning and private living. Progress in Planning, 58(2), 141-227.

[19] Merriam-Webster. 2017. [access 10.03.2017] https://www.merriamwebster.com/dictionary/livability .

[20] Mercer 2017 Quality of living ranking. [cit 10.03.2017] https://www.imercer.com/content/mobility/quality-of-living-city-rankings.html.

[21] People in the EU - statistics on geographic mobility, 2015. [cit. 10.03.2017] http://ec.europa.eu/eurostat/statistics-explained/index.php/People_in_the_EU__statistics_on_geographic_mobility\#Main_statistical_findings.

[22] Prentice R., Andersen V. 2000. Evoking Ireland. Modelling tourist propensity, Annals of tourism Research, 27(2), 501-505.

[23] Quality of Life in European Cities 2015. Flash Eurobarometer. 2016. [cit. 10.03.2017] http://ec.europa.eu/regional_policy/sources/docgener/studies/pdf/urban/survey2015 en.pd f.

[24] Rybakovas E. 2016. Differentiate Patterns of Individually Perceived Quality of Life in Big Cities, Towns and Rural Areas. Inzinerine Ekonomika-Engineering Economics, 27(5), 557-567.

[25] Scogin F.,Morthland M., DiNapoli E.A., LaRocca M., Chaplin W. 2016. Pleasant Events, Hopelessness, and Quality of Life in Rural Older Adults. Journal of Rural Health, 32(1), 102-109.

[26] State of the English Cities (2006). [cit. 10.03.2017]

http://webarchive.nationalarchives.gov.uk/20060731065549/http://communities.gov.uk/pu b/4/StateoftheEnglishCitiesVolume1PDF33Mb_id1164004.pdf.

[27] Survey on perception of quality of life in 75 European cities. 2010. European Commission. [cit. 10.03.2017]

http://ec.europa.eu/regional_policy/sources/docgener/studies/pdf/urban/survey2009_en.pd f.

[28] Survey on Quality of life in cities. [cit. 10.03.2017] http://ec.europa.eu/eurostat/web/cities/perception-surveys.

[29] Urban Audit Perception Survey. Local Perceptions of Quality of Life in 31 European Cities. 2005. [cit. 10.03.2017] http://ec.europa.eu/public_opinion/flash/fl_156_en.pdf. 
20th International Scientific Conference AMSE

Applications of Mathematics and Statistics in Economics 2017

Szklarska Poręba, Poland

30 August 2017 - 3 September 2017 